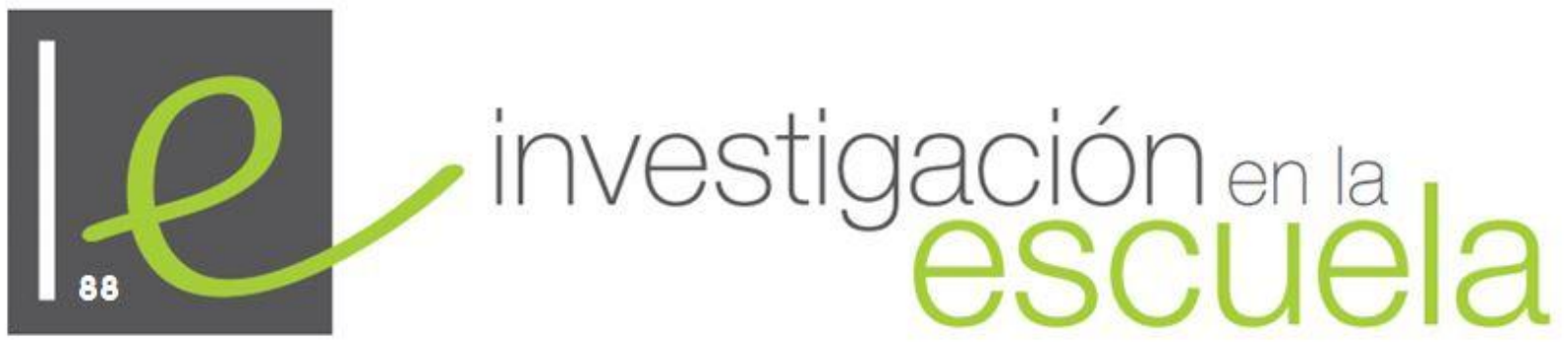

Revista académica evaluada por pares y de acceso abierto

\title{
Análisis bibliométrico de la revista Investigación en la Escuela (1987-2015)
}

\author{
Soledad García Gómez. \\ Universidad de Sevilla \\ España
}

Citación: García-Gómez, S. (2016). Análisis bibliométrico de la revista Investigación en la Escuela (1987-2015). Investigación en la Escuela, 88, 22-45. Recuperado de: www.investigacionenlaescuela.es/artoculos/R88/R88-2.pdf

Resumen: La trayectoria de la revista Investigación en la Escuela a lo largo de tres décadas se describe en este artículo. Se ha realizado un análisis bibliométrico de los ochenta y siete números publicados entre 1987 y 2015. Tras una revisión de los indicadores más utilizados en este tipo de trabajos, se ha procedido a llevar a cabo un análisis de los números y de los artículos a partir de los siguientes indicadores: responsables de la publicación, aspectos formales, temáticas centrales, autoría de los artículos, género, etapa educativa, área de especialización, ámbito geográfico, tipo de artículo y contenido, entre otros. Se trata de un estudio descriptivo de la revista que retrata su evolución y que permitirá informar la toma de decisiones para la nueva época que afronta con su publicación abierta en línea.

Palabras clave: "análisis bibliométrico"; "revista"; "investigación”; "educación”.

Bibliometric analysis of journal Investigación en la Escuela (1987-2015)

Abstract: The progress of the Spanish educational journal Investigación en la Escuela along three decades is described in this paper. Eighty seven numbers of the journal published between 1987 and 2015 have been analyzed. Other bibliometric analysis have been reviewed in order to identify the best bibliometric data to be picked up of each article. We have analyzed each number and each paper paying special attention to: journal management, formal features, core journals, authors, 
gender, educational stage, subjects, geographical distribution of the authors, article type and contents. It is a descriptive study of this journal that shows its trajectory and that will inform the decision making process for this new period as an online journal.

Key words: "bibliometric analysis"; "journal"; "research"; "education".

\section{Analyse bibliométrique de la revue Investigación en la Escuela (1987-2015)}

Resumè: Dans cet article on décrit le parcours de la revue Investigación en la Escuela au long de trois décennies. Nous avons effectué une analyse bibliométrique de quatre-vingt-sept numéros publiés entre 1987 et 2015. Après un examen des indicateurs les plus utilisés dans ce type de travail on a procédé à effectuer une analyse des numéros et des articles à partir des indicateurs suivants: les responsables de la publication, les aspects formels, les thèmes centraux, les auteurs des articles, le genre, l'étape éducative, le domaine d'expertise, la zone géographique, le type d'article et son contenu, entre autres. Ceci est une étude descriptive de la revue qui reflète son évolution et qui permettra d'éclairer la prise de décisions pour la nouvelle ère face à la publication en ligne et ouverte. Mosts clé: "analyse bibliométrique"; "revue"; "recherche"; "èducation".

\section{Introducción}

La revista Investigación en la Escuela ${ }^{1}$ nació en 1987 en el seno del Departamento de Didáctica de las Ciencias Experimentales y Sociales de la Escuela Universitaria de Formación del Profesorado de EGB (Educación General Básica) de la Universidad de Sevilla. Vio la luz en un momento crucial de la Historia de España: se había estrenado la segunda legislatura socialista con mayoría absoluta, era reciente el acceso del país a la Comunidad Económica Europea y se estaba experimentando un fuerte desarrollo económico. El Ministerio de Educación y Ciencia, a cargo de José María Maravall, se centró en el diseño del prometido cambio cualitativo para el sistema educativo. Se publicó en ese mismo año el Proyecto para la Reforma de la Enseñanza (MEC, 1987). El ministro Maravall fue sustituido en 1988 por Javier Solana Madariaga, en cuyo mandato se promulgó la Ley Orgánica de Ordenación General del Sistema Educativo (LOGSE, 1990). Nos situamos, pues, en la antesala de unos acontecimientos muy significativos en la historia legislativa española en materia de Educación (De Puelles Benítez, 2008). El proceso previo a la nueva legislación fue intenso y no estuvo exento de importantes contradicciones, como ha explicitado Zufiaurre (1994). En Andalucía, en particular, se llevaba a cabo en esos años la experimentación de la Reforma del Ciclo Superior de la EGB (Pérez Gómez y Gimeno Sacristán, 1994), que supuso un hito en la trayectoria de un amplio sector del profesorado.

Los últimos años de la década de los 80, durante los cuales se fue gestando la LOGSE, también fueron convulsos, sucediéndose numerosas e intensas reivindicaciones por parte, sobre todo, de los estudiantes de las Enseñanzas Medias. Fue un periodo de ilusión para gran parte del profesorado, que participaba en los procesos de experimentación de las que habrían de ser (y solo fueron parcialmente) las nuevas directrices legislativas. Una parte importante del colectivo de docentes de los Movimientos de Renovación Pedagógica confiaba en hacer realidad (en un marco legal) otra forma de hacer escuela (Hernández Díaz, 2011). Los Centros del Profesorado (CEP) habían nacido en 1984 (dos años más tarde en Andalucía) y se presentaban como un recurso de y

\footnotetext{
${ }^{1}$ La dirección de la página web de la revista es http://www.investigacionenlaescuela.es/. Su ISSN es 0213-7771, y el nuevo ISSN (on line) es 2443-9991.
} 
para el profesorado, impulsando la formación permanente y la necesaria renovación pedagógica de un sistema educativo aún muy marcado por comportamientos y actitudes poco democráticas.

En este panorama general, tan brevemente descrito, en el departamento universitario anteriormente citado, los profesores de Didáctica de las Ciencias Experimentales Pedro Cañal de León y Rafael Porlán Ariza vieron la necesidad de crear una plataforma estable de comunicación entre el profesorado, para asegurar y potenciar los intercambios que hasta la fecha se habían producido al amparo de las "Jornadas de Estudio sobre la Investigación en la Escuela", que habían comenzado a celebrarse en Sevilla en 1983.

Precisamente, ese mismo año se comenzó a editar otra revista de notable interés en nuestro país, Enseñanza de las Ciencias. En ella, los directores de Investigación en la Escuela tuvieron la oportunidad de publicar artículos en los que iban sentando las bases de un modelo didáctico alternativo, que pivotaba en torno a la incorporación a las aulas de la "investigación escolar" (Cañal y Porlán, 1987 y 1988). Algunas contribuciones previas en esta línea habían visto la luz en otra revista emblemática como Cuadernos de Pedagogía (Cañal, García Díaz y García Pérez, 1980; Porlán y Cañal, 1986a y 1986b).

Han transcurrido ya casi treinta años desde la edición del primer número de Investigación en la Escuela y por ello procedemos en este artículo a ofrecer un análisis bibliométrico de su producción, al objeto de presentar y analizar su contenido, retrato de su propio devenir. De esta forma recorreremos tres décadas de investigación en la escuela, tres décadas que reflejan parte de la historia reciente de la educación en España. En este tiempo también han aparecido numerosas revistas educativas, al son de las nuevas políticas científicas y universitarias (Ruiz-Corbella, Galán y Diestro, 2014).

\section{El análisis bibliométrico: antecedentes en el ámbito educativo}

El estudio realizado responde al interés por conocer cómo ha evolucionado la revista con vistas a encauzar una nueva época. Al no ser expertos en Bibliometría, disciplina compleja incluso para los especialistas en ella (Jiménez-Contreras, 2000), se corre el riesgo de presentar un trabajo incompleto y deficiente. Sin embargo, pensamos que el análisis realizado sí es revelador de aspectos cruciales, que bien podrían orientar las decisiones a tomar de cara al futuro de la publicación. Las intenciones de los análisis bibliométricos son variadas. Los hay centrados en la revisión de la producción de una revista a lo largo de un periodo de tiempo, como es el caso que nos ocupa, mientras, en otras ocasiones, el propósito es hacer el seguimiento de una temática en varias revistas. La contribución de Anta Cabreros (2008) es un ejemplo de esta última modalidad: revisa el tópico "investigación educativa" en revistas españolas durante un periodo de tiempo. Alcaide Muñoz, Garde Sánchez y Rodríguez Bolívar (2012) también se encuadran en este enfoque; revisaron el tópico "e-participación” en treinta y seis revistas. El trabajo de Álvarez López (2015) amplía la perspectiva a la revisión de artículos del ámbito de la Educación Comparada en cinco revistas (19952014).

Si nos centramos en la modalidad de análisis que nos interesa en esta ocasión, el de la producción de revistas españolas del ámbito educativo a lo largo de un periodo de tiempo, localizamos antecedentes tan relevantes como los que se muestran en la Tabla 1. Se constata cómo el cambio de milenio ha dado lugar a muchos de estos trabajos. 
Tabla 1

Referencias de análisis bibliométrico de revistas de educación. Fuente: Elaboración propia.

\begin{tabular}{|c|c|c|}
\hline $\begin{array}{l}\text { Nombre de la revista } \\
\text { (año de aparición) }\end{array}$ & $\begin{array}{c}\text { Periodo } \\
\text { analizado }\end{array}$ & Autoría del análisis bibliométrico \\
\hline Aula Abierta (1973) & 2000-2009 & Granados, Ariza y Gómez-García (2011) \\
\hline Bordón (1949) & $\begin{array}{l}1949-1983 \\
2000-2009\end{array}$ & $\begin{array}{l}\text { Sala Such y Calatayud Soler (1984) } \\
\text { Zych (2011) }\end{array}$ \\
\hline Educación XX1 (1998) & $2000-2009$ & Gómez-García, Ramiro, Ariza y Granados (2012) \\
\hline Enseñanza de las Ciencias (1983) & 1983-1996 & $\begin{array}{l}\text { López Calafí, Salvador Carreño y De la Guardia } \\
\text { Cirugeda (1998) }\end{array}$ \\
\hline Infancia y Aprendizaje (1978) & $1978-2002$ & García, Sánchez, del Río y Arias-Gundín (2002) \\
\hline Pixel-Bit (1994) & $2000-2013$ & $\begin{array}{l}\text { López Meneses, Vázquez Cano y Sarasola Sánchez- } \\
\text { Serrano (2015) }\end{array}$ \\
\hline $\begin{array}{l}\text { Revista Española de Orientación } \\
\text { y Psicopedagogía (1990) }\end{array}$ & 2000-2009 & Ariza, Granados, Ramiro, Gómez-García (2011) \\
\hline $\begin{array}{l}\text { Revista de Investigación } \\
\text { Educativa (1983) }\end{array}$ & $\begin{array}{l}1983-2000 \\
2000-2012\end{array}$ & $\begin{array}{l}\text { Bueno Sánchez y Fernández Cano (2003) } \\
\text { Ariza y Quevedo-Blasco (2013) }\end{array}$ \\
\hline
\end{tabular}

La clave de este tipo de análisis de la producción de las revistas científicas -tanto para el vaciado de la información como para el análisis propiamente dicho- es, sin duda alguna, la identificación de los indicadores que habrán de guiar el proceso. Revisada la literatura pertinente, hemos comprobado que son numerosos y diversos (Sancho, 1990). Algunos de ellos, como iremos viendo, gozan de gran aceptación y son los más habituales. En el ámbito educativo, Fernández Cano y Bueno Sánchez (1998) proponían hace años los siguientes: productividad diacrónica (número de estudios por año), productividad de autores, productividad institucional, citación y contenidos.

A continuación exponemos los indicadores que se explicitan en los estudios recogidos en la Tabla 1. García, Sánchez, del Río y Arias-Gundín (2002) han realizado un análisis de contenido de todos los artículos publicados en la revista Infancia y Aprendizaje a lo largo de veinticinco años. Tras el pertinente registro y codificación de los datos, se ocuparon expresamente de tres tipos de variables o indicadores:

a) de identificación formal o por criterios externos (autores, procedencia, período, etc.);

b) de clasificación por criterios internos o de contenido (origen y género del artículo, metodología de investigación, marcos teóricos de referencia y tematización);

c) de ciclo temporal en la publicación de los artículos.

En el caso del análisis bibliométrico de la revista Bordón los indicadores fueron: el año de publicación, el tipo de estudio, el tipo de muestra, el número de autores, la procedencia, la filiación, el idioma de publicación, los años de publicación de los artículos referenciados en los documentos objeto de estudio y citas de los mismos en el INRECS (Zych, 2011). El equipo de profesoras de la Universidad de Granada, que ha realizado este tipo de análisis para varias revistas como Educación XX1, Aula Abierta y Revista Española de Orientación y Psicopedagogía, ha enfocado sus trabajos revisando año de publicación, índice de autoría, filiación institucional (universidad de procedencia) y nacionalidad de los autores, idioma de publicación, tipo de artículo, temática general y número de referencias por año en cada artículo.

En los últimos años, dados los cambios experimentados en el ámbito bibliométrico y en la evaluación de la labor investigadora del profesorado universitario, se han ido incorporando nuevos indicadores vinculados a los índices de impacto. Según Ruiz-Pérez, Delgado López-Cózar y JiménezContreras (2010), “entre 1996-2004 se inicia la formulación de los indicadores de calidad de la 
investigación, quedando asociados casi exclusivamente con las publicaciones de impacto (revistas JCR)" (p. 898). Sin embargo, atendiendo al trabajo de Fuentes, Luque y López Gómez (2012), esta tónica tendría que ser matizada ya que el listado de revistas JCR no incluye todas las revistas educativas de calidad:

La producción científica educativa española -de calidad- no se reduce a su expresión en el JCR. No son pocas las revistas educativas nacionales que atienden a diversos criterios de calidad y que dan difusión a trabajos significativos para la investigación educativa o más concretamente para determinadas áreas para las que algunas revistas, pese a no estar en el JCR, son auténticos referentes (p. 214).

Ruiz-Corbella, Galán y Diestro (2014) sostienen que los actuales sistemas de valoración de la calidad de las revistas educativas tienen que ir cambiando, entienden que "las nuevas métricas podrían aportar una lectura mucho más rica, objetiva, fiable y transparente del impacto de los artículos" (p. 22).

\section{Objeto de estudio y procedimiento de análisis}

Como ya hemos anunciado, el objeto de este análisis bibliométrico es la revista Investigación en la Escuela, el conjunto de los ochenta y siete números publicados entre 1987 y 2015 (periodicidad cuatrimestral). Esto supone la revisión de alrededor de setecientos artículos, al abarcar casi tres décadas completas de publicación ininterrumpida.

En función de nuestros intereses, y atendiendo a los antecedentes en este tipo de trabajos, se ha seleccionado una serie de indicadores que a veces se refieren a los números completos y, en otras ocasiones, a los artículos o contribuciones en particular.

Los indicadores considerados son:

- Números:

- Responsables de la publicación (editores, dirección, consejo asesor, equipo de colaboradores, coordinación general y en América Latina).

- Aspectos formales (portada, extensión, número de textos, estructura interna, índice, editorial).

- Temáticas centrales (monográficos).

○ Números especiales.

○ Indexación.

- Artículos:

- Autoría (número de autores/as, género, etapa educativa, área de especialización, vinculación con el Grupo Investigación en la Escuela, los grupos DIE y GAIA y/o con la Red IRES, ámbito geográfico).

O Modalidad o tipo.

- Contenido.

Mediante el manejo manual de todos los ejemplares de la revista (al ser más ágil que la consulta en la página web) se han ido extrayendo los datos seleccionados de cada número y artículo. Esta información se ha volcado en tablas elaboradas para tal propósito. Es obvio que el proceso no ha sido completamente lineal y que con los avances en la tarea iban sugiendo nuevos focos de interés y nuevos datos a recabar. Tras completar este laborioso, ingente y minucioso proceso, se han contabilizado todos los datos requeridos según los indicadores establecidos, se han calculado porcentajes y se ha procedido a la pertinente descripción de los hallazgos. Otra parte del análisis ha 
tenido un carácter más cualitativo, por lo que ha requerido un análisis de contenido. En todo caso, la mera lectura de los resultados creemos que ya es reveladora de informaciones relevantes.

\section{Resultados del análisis bibliométrico}

\section{Análisis de los números de la revista}

\section{Responsables de la publicación}

La edición. El primer número fue editado por los profesores Porlán Ariza y Cañal de León. A partir del número 2 y hasta el 12, la edición corrió a cargo del Servicio de Publicaciones de la Universidad de Sevilla, pasando en 1991 (número 13) a ser editada por el Grupo Investigación en la Escuela y la empresa Díada Editoras, S.L. Desde el número 20 (1993) en adelante se especifica que edita el Equipo de Dirección de la revista y la editorial Díada, y, a partir de 1995 se limitará a ésta. El copyright de la publicación lo ostenta la editorial junto al Equipo de Dirección de la revista.

La dirección. A lo largo de los años han sido continuos y numerosos los cambios acontecidos en relación a la dirección de la revista. Esta fue creada por los profesores Rafael Porlán y Pedro Cañal, directores ambos de los primeros ocho números. A partir del número 9 (1989) la dirección deja de estar exclusivamente a su cargo para hacerse extensiva a otros miembros del Grupo Investigación en la Escuela. En 1992 se producen variaciones y ya no aparece el nombre del Grupo Investigación en la Escuela como tal. El Equipo de Dirección se estabiliza a partir del número 20 (1993) con alguna variación de componentes. En los años sucesivos se siguen produciendo altas y bajas en el equipo. Hay que destacar que en 1999 deja de formar parte del Equipo de Dirección uno de los creadores de la revista: Rafael Porlán.

Dos años después el Equipo de Dirección de la revista se configura con los siguientes miembros (que permanecerán casi durante una década completa): Pedro Cañal de León, J. Eduardo García Díaz, Francisco F. García Pérez, José Martín Toscano, Gabriel Travé González y Francisco J. Pozuelos Estrada. A partir de 2010 se incorporan Nicolás de Alba Fernández y Ana Rivero García y abandonan dos componentes históricos: José Martín Toscano y J. Eduardo García Díaz (miembros desde 1989). Este equipo, integrado por profesorado de las universidades de Huelva y Sevilla, es el responsable de la revista hasta la fecha.

Consejo Asesor. Éste estuvo formado inicialmente por dieciocho profesionales (la mayoría profesorado universitario), de los cuales cinco eran extranjeros (Reino Unido, Francia, Italia). Se mantuvo estable hasta 1992 cuando se incorporan dos profesores y cesan seis. Apenas se producen altas y bajas en los años siguientes, siendo un consejo permanente de trece miembros (todos varones).

Colaboradores de Redacción. Inicialmente eran diez docentes, de los cuales la mitad aproximadamente desempeñaban su labor en educación primaria y secundaria y la otra mitad en la universidad. Algunos de ellos se incorporarían más tarde al Equipo de Dirección. Transcurridos los primeros tres años se amplía el equipo con profesorado de otras universidades (Valencia, Málaga y Granada), alcanzando los veinte miembros. Con el paso de los años se produjeron varias bajas, situándose en torno a las dieciséis personas y primando de forma notable el profesorado universitario en detrimento del de otras etapas, sobre todo, de educación primaria. En torno al año 
2001 vuelve a incrementarse el número de colaboradores, siendo ya testimonial la presencia de profesorado no universitario (poco más del 15\%).

A partir de 2008 la revista cuenta con veinticinco colaboradores de redacción y en 2010 cambia la denominación a Consejo Científico, integrado por veinte colaboradores, de los cuales dos son profesores de secundaria y prácticamente la mitad son mujeres. La filiación institucional mayoritaria es la Universidad de Sevilla, los demás trabajan en las universidades de Málaga, Cádiz, Granada, Córdoba, Valencia, Autónoma de Barcelona y Complutense de Madrid. Podemos concluir que el equipo se ha ampliado y ha virado hacia el ámbito universitario en estas casi tres décadas. Su función ha sido fundamentalmente la de evaluadores de los artículos recibidos para su publicación.

Colaboraciones de redacción. Otro dato interesante para conocer y comprender la evolución de esta publicación es la coordinación de los números. A partir de 1992 cada número contaría con un coordinador general (o más, siendo habitualmente al menos uno miembro del Equipo de Dirección).

La persona que más números ha coordinado a nivel general es uno de los creadores de la revista, el profesor Pedro Cañal, que ha desempeñado esta labor en un 23\% de las ocasiones. Le siguen Francisco F. García y Gabriel Travé con un 14\% y un 12\% respectivamente. J. Eduardo García y Francisco J. Pozuelos atesoran un 10\% de las coordinaciones

También a partir de 1992 la revista pasó a contar con coordinadores para América Latina, quienes ejercerían funciones de distribución editorial en sus países respectivos. Comenzó esta labor la profesora mexicana Antonia Candela y después se amplió a otros colegas de su país, de Argentina y de Venezuela.

En las dimensiones analizadas en este subapartado, los datos muestran que la presencia de mujeres es claramente inferior a la de hombres.

\section{Aspectos formales}

Portada. La revista ha contado a lo largo de su trayectoria con cuatro diseños distintos de portada. La diversidad de colores para identificar a los tres números de cada año también ha sido constante a lo largo de dos periodos que suman veinte años en total (1987-1990 y 2000-2015). Las figuras 1, 2, 3 y 4 reproducen varias portadas representativas de los cambios que se han ido produciendo a nivel de diseño.
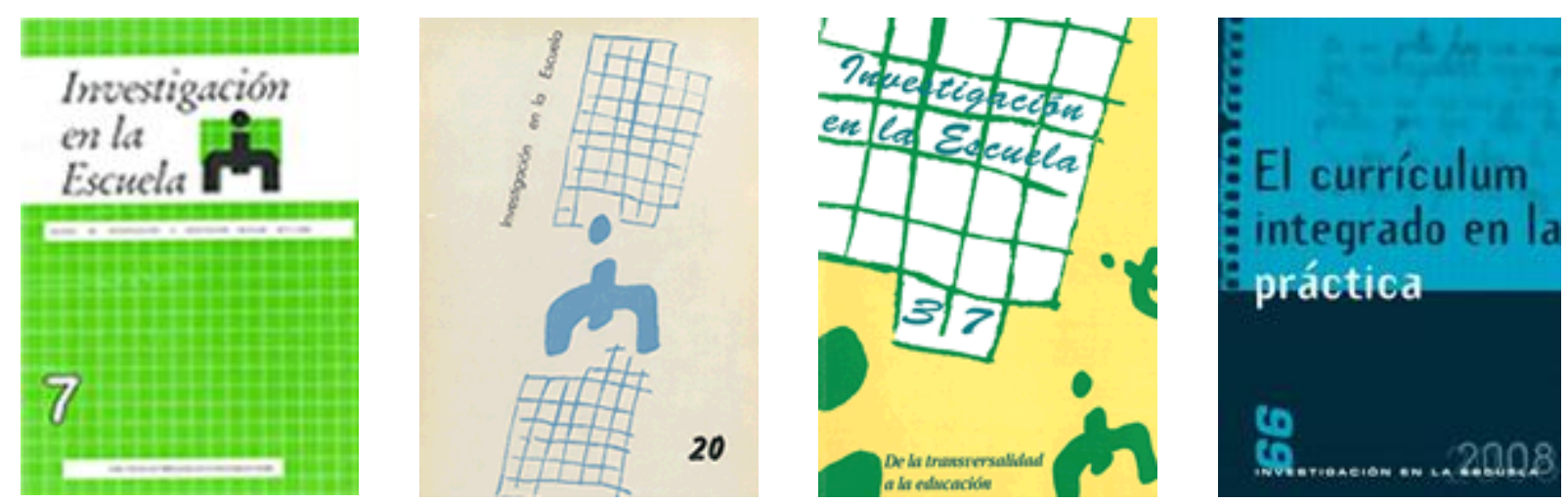

Imagen 1. Portadas de los números 1 a 12 (1987-1990); 13 a 21 (1991-1993); 22 a 39 (1994-1999); y a partir del número 40 (2000-actualidad) 
En los dos primeros diseños de portada se incluía el subtítulo "Revista de Investigación e Innovación Escolar”. A partir del número 22 (1994) éste se elimina y aparecen rotulados enunciados que identifican la temática principal de los artículos, pues pasan a ser números monográficos. Es notable que desde el número 40 (2000) en adelante el nombre de la revista reduce considerablemente su tamaño y lo más visible pasa a ser el nombre del monográfico. El simbólico anagrama de la revista, recogido en la figura 5 , quedaría solo en la contraportada.

El subtítulo inicial reaparece a partir de 2004 aunque lo hará en el interior y añadiendo el término Internacional (Revista Internacional de Investigación e Innovación Escolar).

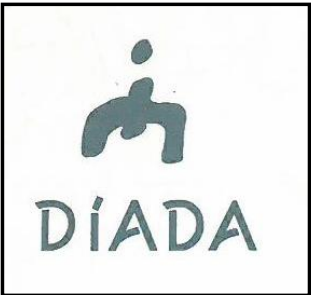

Imagen 2. Anagrama de la revista Investigación en la Escuela

Extensión. La extensión de cada número ronda las 115 páginas en la mayoría de los casos. No ha habido notables variaciones con el paso de los años, pese a haber habido modificaciones en otros aspectos.

Número de textos. La revista ha publicado a los largo de estos años artículos, entrevistas, editoriales, manifiestos, fichas didácticas, informes, convocatorias y reseñas bibliográficas. Si nos limitamos a los artículos podemos decir que en cada número han oscilado entre 8 y 9 , excepto en el periodo 1991-1993, cuya media fue de 7 artículos.

Estructura. La estructura interna de la revista ha variado en distintos periodos de tiempo. Tras un primer número genérico, en el editorial del segundo se presenta la estructura a seguir, la cual será estable hasta el número 12 (1990):

- Fundamentos

- Investigación e Innovación escolar (se llamará Investigación, innovación y evaluación a partir del número 13)

- Fichero didáctico

- Información/Informes

A partir del número 19 (1993) se introducen ligeras modificaciones en la estructura interna: desaparecen los apartados Fichero didáctico e Informes. En 1995 se elimina la estructuración por apartados, que se recuperará en 2012 con esta división:

- Introducción editorial

- Monografía

- Investigación didáctica

Es de destacar que en distintos momentos la revista sirve de canal de difusión de una serie de planteamientos por parte del equipo responsable de la misma - o de otros colectivos afines - a través de la inclusión al final del número de los denominados Manifiestos. Los títulos de los mismos son:

- "Investigación educativa y apertura curricular" (no 19, 1993).

- "Plataforma asturiana de educación crítica" (n 24, 1994). 
- "Sobre el sistema andaluz de formación permanente del profesorado" (n $\left.{ }^{\circ} 31,1997\right)$.

- "El conflicto educativo en Argentina" ((no 39, 1999).

- “Es necesaria una contrarreforma educativa?” (n 43, 2001).

- "Universidad y Europa: No al Servilismo Neoliberal” (n 57, 2005).

- "Manifiesto pedagógico NO ES VERDAD” (nº6, 2008).

Índice. El índice siempre ha ocupado la contraportada de la revista, aunque a partir del número 40 (2000) cambió el formato (imagen 3) y se omitió la paginación de los artículos. Desde entonces aparece el índice completo al inicio de cada número, antes del Editorial o Introducción Editorial.
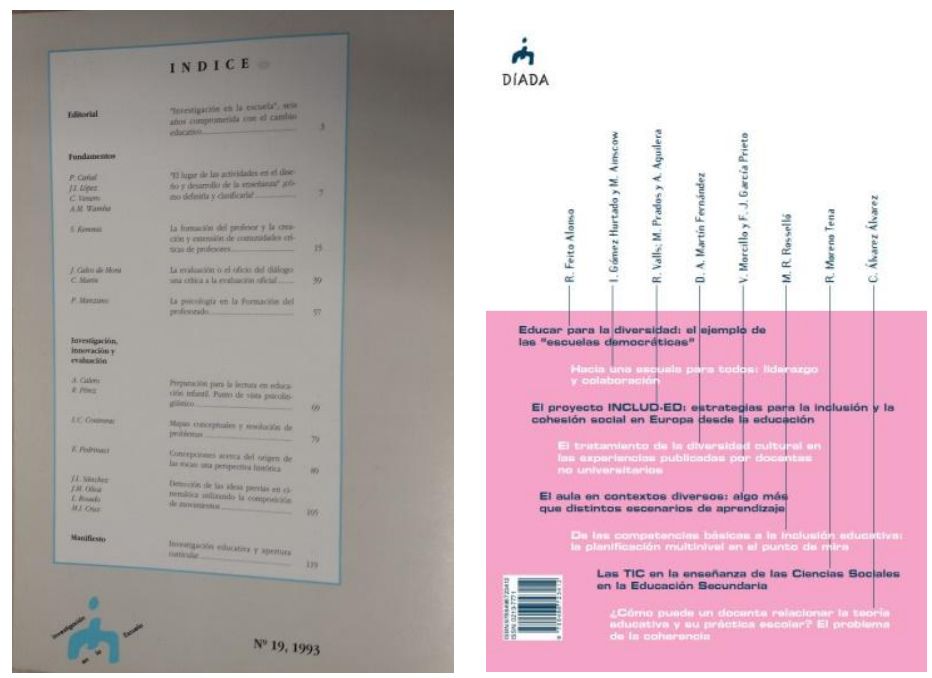

Imagen 3. Cambios en la presentación del índice en la contraportada

Editorial. Siempre se ha incluido un Editorial aunque su enfoque haya cambiado. Inicialmente era un pronunciamiento sobre un tema candente o de especial relevancia y, poco a poco, ha ido centrándose más en una introducción al número, justificando la temática y presentando las contribuciones.

La nube de palabras (imagen 4) elaborada a partir de los títulos de los editoriales de la revista da idea de cuáles han sido los términos más utilizados: escuela, educación, enseñanza, práctica, formación, investigación en la escuela, profesorado, etc. 


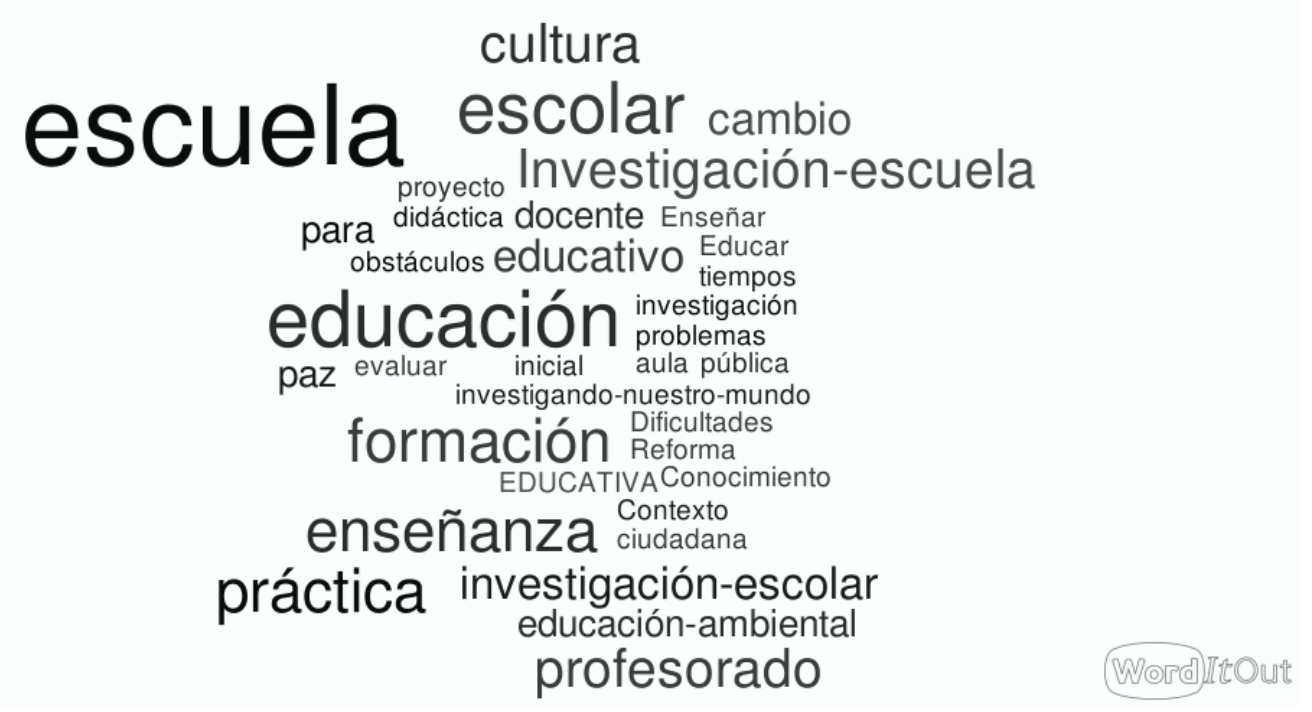

Imagen 4. Nube de palabras a partir de los títulos de los editoriales. Fuente: Elaboración propia.

Son de destacar los editoriales de los números 13 y 19 por analizar la evolución de la revista tras transcurrir cuatro y seis años respectivamente desde su aparición. En el editorial del número 13 (1991) se decía que la revista había superado su "etapa infantil" y que no se ajustaba plenamente al modelo de partida. Entraba en una fase caracterizada como de "adolescencia contradictoria". En 1993 (núm. 19) se anunciaban cambios en los contenidos y en la estructura interna, al considerar que hacía falta "conectar más claramente con las necesidades y expectativas de un profesorado implicado en procesos de transformación educativa". Se confiaba en lograr una revista que fuese "un foro más participativo, atractivo y actual".

Monográficos. En ese mismo número 19 se enfatizaba la necesidad de que cada ejemplar debía girar en torno a una idea nuclear. Así pues, ya a partir del 22 (1994) se publican números monográficos. Las temáticas abordadas de esta forma han sido muy diversas, abarcando muchas dimensiones del ámbito educativo. Entre 1994 y 1999 los monográficos se ocuparon principalmente de:

a) Planteamientos constructivistas. Títulos: Las ideas de los alumnos, El conocimiento escolar o Constructivismo y didáctica.

b) El profesorado. Títulos: La formación inicial del profesorado de Primaria y Secundaria, La formación permanente del profesorado o El trabajo docente.

c) La educación infantil y primaria. Títulos: Educación infantil: la reforma pendiente, La enseñanza primaria boy o Investigando Nuestro Mundo.

Entre los años 2000-2015 la diversidad de temáticas ha sido aún mayor. Solo hay algunos tópicos que, con ciertas variaciones, han dado sentido a varios monográficos. Es el caso de la formación del profesorado, la investigación escolar, la educación ambiental o los planteamientos alternativos a la escuela actual. Subrayamos el interés de la revista por ocuparse del profesorado en general y de su formación en particular. En este periodo hay títulos como: Formación inicial del profesorado y relevancia de la práctica, Formación del profesorado y práctica de la enseñanza o Estudios de caso en formación del profesorado. También son habituales los monográficos que se centran en aspectos más metodológicos vinculados a la investigación escolar. Algunos títulos: Activismo e investigación escolar, Actividades y estrategias de enseñanza, Experiencias e Investigaciones Didácticas. 
En este último periodo se plantean contenidos no habituales en la revista y se hace al hilo de la necesidad de generar cambios en más esferas del ámbito educativo. Esta situación se refleja en títulos como: Orientación educativa y cambio escolar. Llama la atención otra forma de abrir horizontes que es denominando al monográfico "Educar para...", en esta línea están: Educar para la participación ciudadana, Educar para la diversidad, Educación para la sostenibilidad y la salud, etc. También últimamente la revista se ha hecho eco de propuestas o enfoques emergentes. Es el caso, por ejemplo, de números dedicados a internet, a la evaluación de las competencias, a la crisis económica, etc.

Números especiales. A lo largo de estos casi treinta años se han publicado varios números que hemos denominado especiales por distintos motivos, los cuales pasamos a presentar brevemente:

\section{7 (1995) y 51 (2003): Investigando Nuestro Mundo y Proyecto Curricular Investigando}

Nuestro Mundo (6-12). Se destacan estos dos números por ser portavoces del proyecto curricular centrado en la investigación escolar, propuesto inicialmente por miembros del extinto Grupo Investigación en la Escuela (reagrupados posteriormente, con la incorporación de nuevos miembros, en el Grupo GAIA).

43 (2001): Investigación en la escuela, quince años después. Con motivo del aniversario se invita a miembros del Consejo Asesor de la revista a escribir artículos que ofrezcan una panorámica global sobre los problemas y obstáculos a superar para avanzar en otro modelo educativo.

47 (2002), 49 (2003) y 73 (2011): Dificultades y obstáculos para el cambio en el aula (I) y (II), y Obstáculos y dificultades para la investigación escolar. Estos tres ejemplares son sensibles a los problemas que existían y siguen existiendo para llevar los planteamientos didácticos investigativos a las aulas. La revista, junto a su afán por divulgar experiencias potentes de investigación escolar, denuncia los obstáculos y las dificultades que se afrontan como una vía para superarlos.

48 (2002): El panorama educativo en la actualidad. Pensamiento y obra de J. Delval . Este número iniciaba una nueva modalidad de monográficos (que no tendría continuidad), dedicada a autores relevantes por sus aportaciones al pensamiento educativo. Tras su perfil biográfico incluye varios artículos escritos por el propio Juan Delval, así como una entrevista que le realizó el coordinador del número.

72 (2010): Luis del Carmen y la investigación escolar. Este número es un homenaje al colega Luis del Carmen fallecido prematuramente, al que Pedro Cañal se refiere en el Editorial con estas palabras: "fue un excelente profesor, investigador y activista, en el mejor sentido del término". Se incluyen varios artículos escritos por él, algunos de los cuales van acompañados de unas notas introductorias y comentarios realizados por miembros del Equipo de Dirección de la revista.

77 (2012): Francesco Tonucci y la escuela que queremos. Como se declara en el Editorial de este número, Tonucci fue el referente de un proyecto desarrollado en Sevilla para que el alumnado de todas las etapas del sistema educativo delineara y propusiera el modelo de escuela que deseaba. En marzo de 2011 se celebró la jornada de presentación e intercambio de estas propuestas en la Facultad de Ciencias de la Educación de la Universidad de Sevilla. Algunas de las contribuciones aparecen en este monográfico. 
87 (2015): Experiencias e Investigaciones Didácticas. Reseñado aquí por ser el último número de la primera época de la revista, que da paso a su edición en formato digital en abierto.

\section{Indexación}

En 2004 aparece al final de la revista la relación de catálogos, directorios y bases de datos donde está visible. Entre otros lugares, actualmente está indexada en:

- CINDOC Instituto de Estudios Documentales sobre Ciencia y Tecnología.

- REBIUN Catálogo Colectivo de la Red de Bibliotecas Universitarias Españolas.

- DIALNET Catálogo Colectivo de la Universidad de La Rioja.

- COPAC Catálogo Colectivo (Reino Unido) Consortium of University Research Libraries (CURL).

- AMICUS Catálogo Colectivo de Bibliotecas Canadienses.

- SUDOC Catálogo colectivo (Francia).

- ZDB Catálogo colectivo (Alemanya).

- LATINDEX Sistema Regional de Información en Línea para Revistas Científicas de América Latina, el Caribe, España y Portugal.

- IRESIE Banco de datos sobre educación iberoamericana.

- RESH.Revistas Españolas de Ciencias Sociales y Humanas (CINDOC - CSIC).

- DICE. Difusión y Calidad Editorial de las Revistas Españolas de Humanidades y Ciencias Sociales y Jurídicas (CINDOC - CSIC - ANECA).

- IN-RECS. Índice de impacto de las Revistas Españolas de Ciencias Sociales.

- CARHUS-DURSI.

- UCUA. Unidad para la Calidad de las Universidades Andaluzas.

En relación con los índices de impacto, hay que reseñar que en CARHUS+ 2014 ha obtenido la calificación D y en CIRC 2015 la C. Conviene dejar constancia de que un obstáculo importante para ascender o no en estas clasificaciones es el estar en abierto. Recordamos que la revista ha dado ese paso muy recientemente.

\section{Análisis de los artículos publicados}

Autoría de los artículos. Este indicador del análisis bibliométrico se desglosa en una serie de aspectos como son el número, el género, la filiación institucional, el área de especialización y el enclave geográfico.

Número. Se ha llevado a cabo un análisis de la cantidad de autores y autoras que firman cada artículo. Nos propusimos conocer si abunda la autoría individual o compartida y, en este caso, si responde a equipos de trabajo que se identifican como tales. Revisados los numerosos artículos, los datos ofrecen una información clara y contundente (Figura 1). La autoría individual y por parejas acaparan casi el 80\% de los casos (la autoría individual ronda el 60\% y la dual el $24 \%$ ). Los artículos firmados por tres o más autores o autoras no llegan al 20\%. Solo en un $2 \%$ de los casos se firman los textos como equipos de trabajo o de investigación. Las diferencias entre cómo se presentan los miembros de estos equipos son notorias. En algunos casos se nombran todas las personas componentes del equipo y en otros no; se indica la relación del equipo con la Red IRES; son equipos de investigación de universidades; son equipos de docentes de un mismo centro; docente 
universitario junto a equipo de profesorado de secundaria; etc. Este tipo de autoría es muy escasa y no se aprecian diferencias según períodos de tiempo; sí es evidente que no es una tendencia al alza.

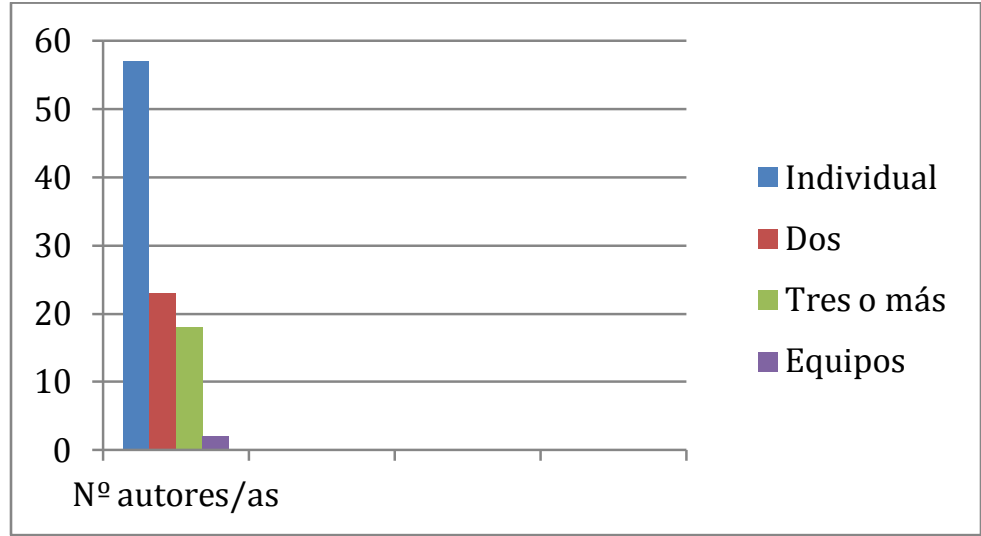

Figura 1. Número de autores y autoras por artículo. Fuente: Elaboración propia.

Género. Uno de los aspectos revisados y analizados es la presencia de autoras y autores, el género de la autoría de los artículos publicados (se excluyen reseñas, manifiestos, etc.). Se ha contabilizado el número de mujeres y de hombres que firman artículos (en algunos casos de forma conjunta). Han sido excluidos los textos cuya autoría viene reflejada solo con los apellidos y las iniciales del nombre (números de 2004). Se pueden establecer dos períodos, pues a partir del cambio de siglo se aprecia un punto de inflexión en la tónica general (Figura 2).

Entre 1987 y 1999 la autoría es mayoritariamente masculina (media: 69\%), rondando los valores más altos el $80 \%$ de la producción y no bajando en ningún momento del $60 \%$. En cambio, entre los años 2000 y 2015 la presencia de autoras es visiblemente más elevada, la media ronda el $50 \%$. En estos años la horquilla de autoría masculina se mueve entre el 70 y el $40 \%$. Por tanto, se puede afirmar que las mujeres autoras han ido ganando presencia en la revista, dato que se constata además en los dos últimos años en los que rebasan el 50\% en todos los números.

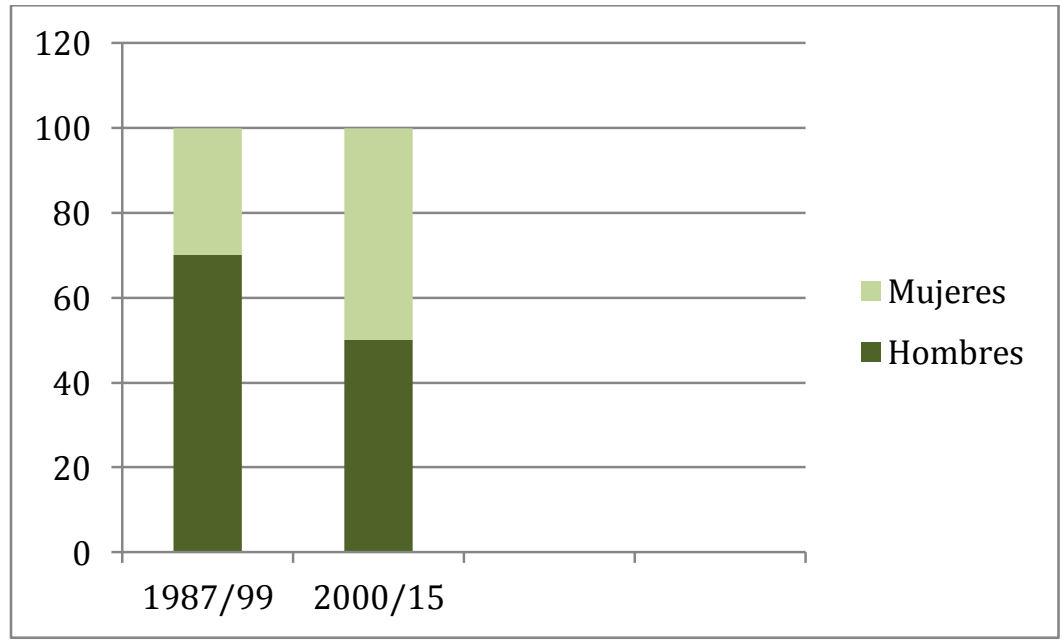

Figura 2. Nivel de autoría masculina y femenina. Fuente: Elaboración propia. 
Mención aparte merecen dos números en particular: el 33 (1997), un monográfico sobre Educación Infantil, es el ejemplar con una mayor participación de autoras (78\%); y el 51 (2003), dedicado al Proyecto Investigando Nuestro Mundo (INM), es de autoría 100\% masculina.

Etapa educativa. Otro dato registrado y analizado es el lugar de trabajo de quienes firman los artículos, lo cual, en definitiva, indica la etapa educativa en la que desempeñan su labor profesional (Figura 3). Las autoras y los autores de los artículos publicados en Investigación en la Escuela están adscritos a universidades en un $85 \%$ de los casos. La presencia de docentes de otras etapas educativas es muy escasa, apenas alcanza el 15\% (uno de cada tres suscribe el texto junto a profesorado universitario). En un 60\% de los casos son docentes de educación secundaria, mientras el $40 \%$ restante lo constituyen maestras y maestros de educación infantil y primaria. Un $6 \%$ de los artículos cuenta con autoría singular (administración educativa, asociaciones u otros organismos), entre la que destaca por ser más numerosa la de personal de los Centros de Profesorado. El profesorado de educación de adultos y de formación profesional prácticamente no tiene presencia alguna.

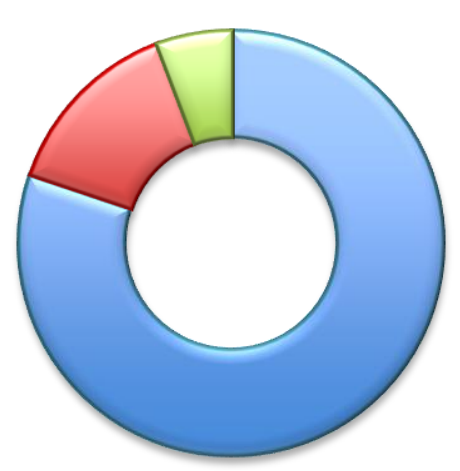

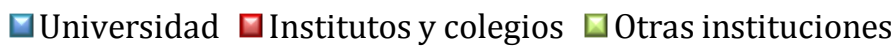

Figura 3. Filiación institucional de autores y autoras. Fuente: Elaboración propia.

Área de especialización. El profesorado universitario que escribe en la revista se adscribe fundamentalmente (cuando así lo especifica) a un departamento de Didácticas Específicas (con distintas denominaciones según las universidades). Las Ciencias Sociales y las Ciencias Experimentales copan la mayoría de los casos (más del 40\%). Le sigue el profesorado de departamentos de Didáctica y Organización Educativa en un $27 \%$ de las ocasiones. A cierta distancia, pero con datos aun relevantes, está el profesorado de las Facultades de Psicología (18\%) y con un 10\% el profesorado de Didáctica de la Matemáticas.

Es muy residual el profesorado de otras áreas de conocimiento, como Sociología, Teoría e Historia de la Educación, Métodos de Investigación, etc. Otras Didácticas Específicas, como las vinculadas a Lengua y Literatura, Música, Educación Física o Idiomas prácticamente no aparecen (véase Figura 4). 


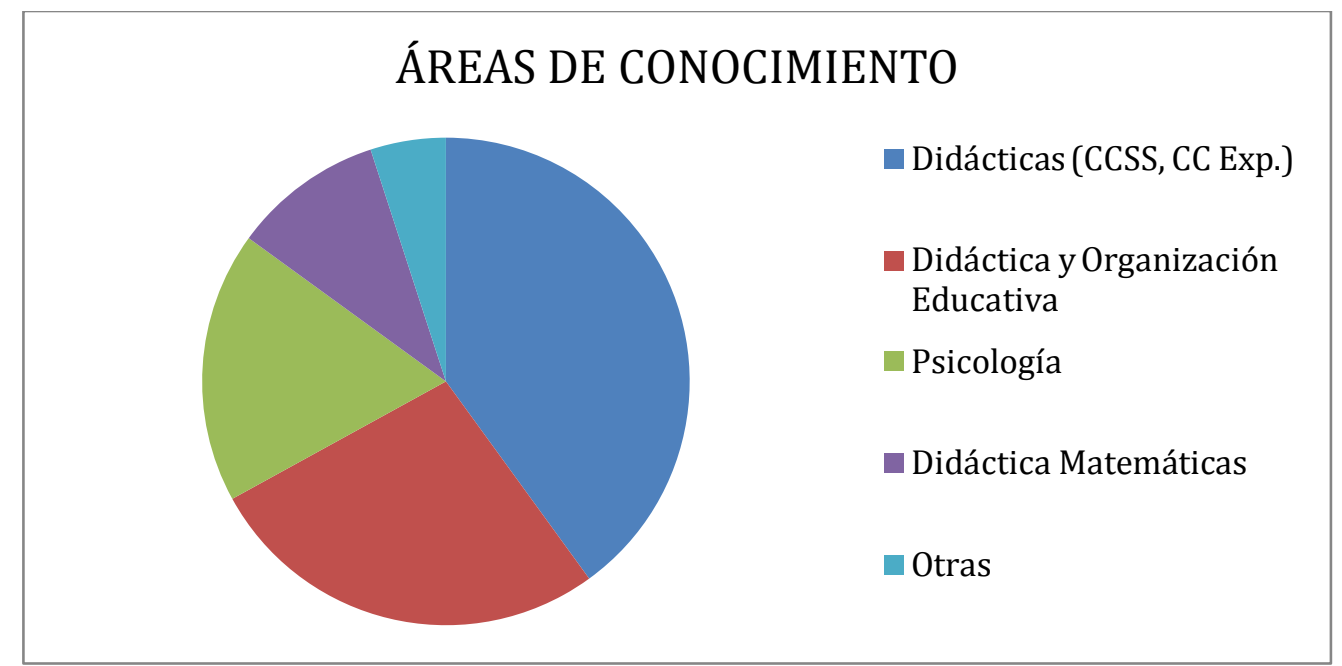

Figura 4. Adscripción de autoras y autores a áreas de conocimiento. Fuente: Elaboración propia.

Vinculación con los grupos Investigación en la Escuela, DIE o GAIA y/o la Red IRES. El grupo Investigación en la Escuela a lo largo de los años experimentó cambios de tal forma que se desgajó en dos: GAIA (Grupo Andaluz de Investigación en el Aula) y DIE (Didáctica e Investigación Escolar). En 1991 se elaboraron los materiales del denominado Proyecto Curricular IRES (Investigación y Renovación Escolar), los cuales darían sentido a la creación de la Red IRES ${ }^{2}$ a finales de esa década. Si tenemos en cuenta las referencias directas que aparecen en los artículos publicados en Investigación en la Escuela, podemos vislumbrar con claridad que más del $20 \%$ de la producción total es fruto de miembros de estos grupos de investigación y/o de personas vinculadas a la Red IRES 3 o al Proyecto Curricular Investigando Nuestro Mundo (INM 6-12).

Ámbito geográfico. Nos ocupamos en primer lugar de desentrañar si todos los artículos son de autoría nacional o no. Encontramos que menos del 15\% de los artículos están firmados por colegas de otros países, que se reparten dos tercios en Latinoamérica y un tercio en Europa, contando con un artículo cuyo autor es australiano (S. Kemmis) y otro norteamericano (A. Sadovnik). Los países con más presencia son, de una parte, México, Colombia, Brasil, Argentina, Chile y Venezuela; y, de otra, Reino Unido, Francia, Italia y Portugal. Prácticamente todos los años hay una media de tres artículos de autores y autoras extranjeros, que se distribuyen en una horquilla de uno a seis textos.

Más de la mitad de los números de la revista incluye algún artículo de autoría extranjera y/o compartida. La década de los 90 es la que aglutina el mayor número de artículos de estas características, apreciándose un notable descenso a partir de 2000, que se agudiza en la década actual. Los números con más artículos de autoría no nacional son el 24 (La didáctica de las ciencias en Europa, 1994), el 25 (¿Cómo enseñar? La didáctica de las ciencias en Europa, 1995), el 36 (Las reformas educativas: análisis crítico) y el 68 (Educar para la participación ciudadana, 2009). El número 24 fue una colaboración con la revista ASTER, recherches en didactique des sciences

${ }^{3}$ La Red IRES (Investigación y Renovación Escolar) (http://www.redires.net) está formada por profesorado y grupos de profesoras y profesores de todos los niveles educativos -infantil, primaria, secundaria, universidad, adultos, educación especial, etc.- que tienen como referente para su trabajo el Modelo Didáctico de Investigación en la Escuela (MIE) (García Pérez y Porlán, 2000; García Pérez, 2000).

${ }^{4} \mathrm{El}$ proyecto INM (6-12) tiene su origen en las propuestas contenidas en el Proyecto de Investigación y Renovación Escolar (IRES). En http://www.uhu.es/gaia-inm/invest_escolar/httpdocs/inm_btn1.php. 
expèrimentales, e incluye dos artículos de autores franceses y uno británico; en el núm. 25 participan autores y autoras de Brasil, México, Argentina y Portugal. El número 36 también fue una colaboración con la revista mexicana Cero en conducta, de ahí que incluya tres artículos de autores de este país. En el núm. 68 las procedencias son: Italia, Suiza, Argentina, Brasil y Colombia.

$\mathrm{Al}$ analizar estos artículos detectamos algunos rasgos de interés:

a) Las contribuciones desde el Reino Unido se concentran en los primeros años de existencia de la revista (hasta 1994), estando en ocasiones vinculadas a actividades del Grupo Investigación en la Escuela (Jornadas, estancias, ponencias), siendo la mayoría traducciones de textos ya publicados. Destaca la presencia, entre otros, de profesionales de renombre de los ámbitos del Currículum y la Psicología como Lawrence Stenhouse, Wilfred Carr, Joan Solomon o Derek Edwards. No disponemos de publicaciones a cargo de profesorado de primaria y/o secundaria, solo de ámbito universitario.

b) Hay autores y autoras, la mayoría latinoamericanos y del ámbito universitario, que comparten autoría con colegas españoles; en ocasiones, estas colaboraciones son fruto de relaciones institucionales. Destaca la presencia recurrente de investigadoras del Departamento de Investigaciones Educativas de la Ciudad de México. Son, asimismo, muy escasos los artículos en los que participa profesorado de etapas no universitarias. Merecen resaltarse tres casos de finales de los 90 protagonizados por maestras colombianas y mexicanas.

c) El autor extranjero que más artículos ha publicado es Francesco Tonucci (Italia), miembro del Equipo Asesor de la revista desde su creación.

Las autoras y los autores españoles se distribuyen por toda la geografía nacional aunque de forma desigual. Incluimos un sencillo panorama por comunidades autónomas (Figura 5).

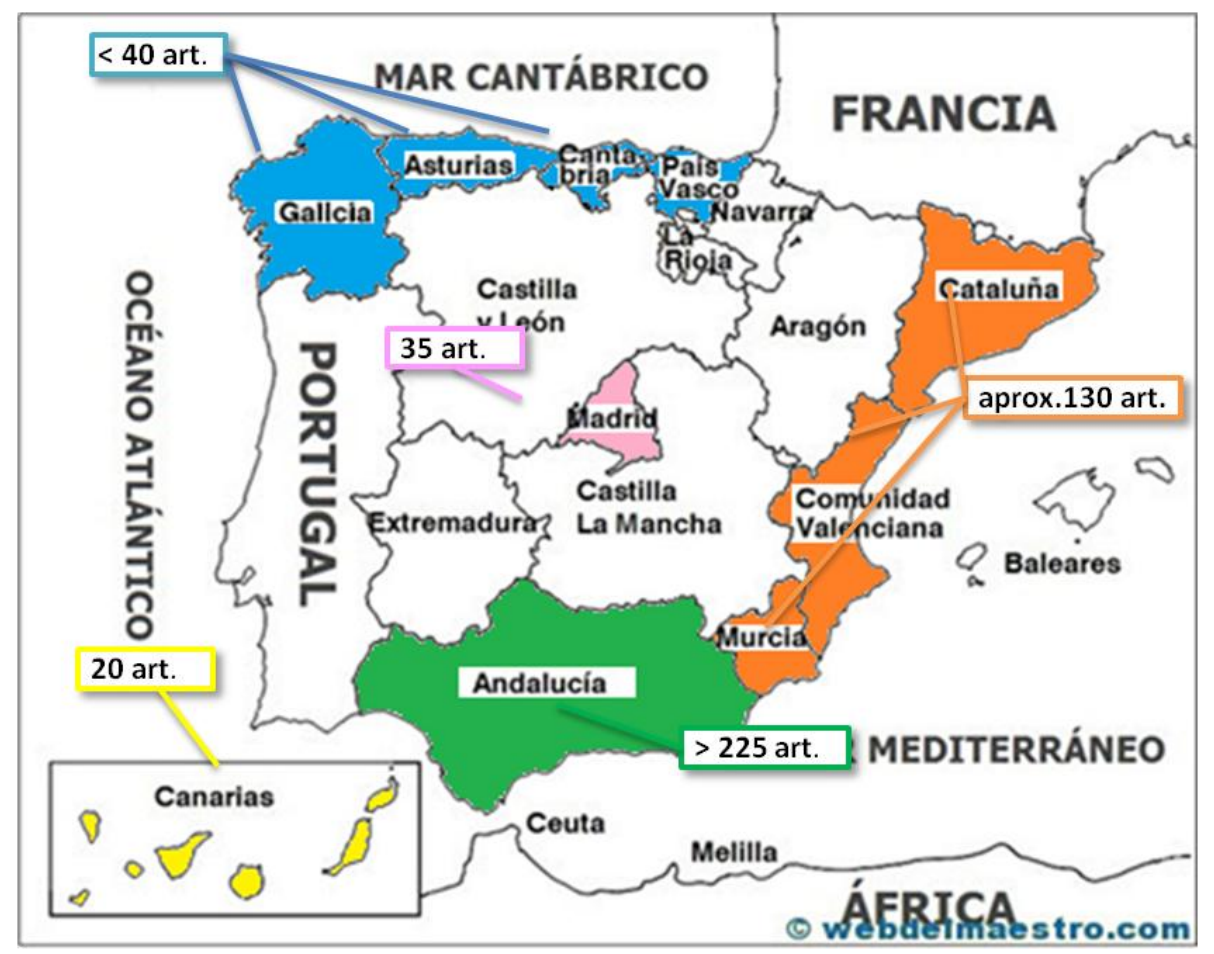

Figura 5. Distribución de artículos por la geografía española. Fuente: Elaboración propia.

A la cornisa cantábrica (Galicia, Asturias, Cantabria y País Vasco) corresponden menos de 40 artículos, mientras que el litoral mediterráneo (Cataluña, Valencia y Murcia) lo triplica, acercándose a 
130. Las Islas Canarias aglutinan unos 20 artículos y Madrid 35. Apenas hay producción del resto de comunidades autónomas; es muy escasa la presencia de las provincias interiores.

Los autores y las autoras que desempeñan su labor profesional en Andalucía representan algo más del 50\% del total, experimentándose un ligero aumento en el presente siglo. En relación a la distribución por provincias hay que destacar que más del $52 \%$ se localizan en Sevilla (o sea, una cuarta parte de la producción total de la revista es de autoría sevillana), a la que sigue Huelva, que se aproxima al 20\%. Este dato indica que los lugares de trabajo de los miembros del Equipo de Dirección de la revista coinciden con más del 70\% del origen de autoras y autores en Andalucía. El resto de provincias cuenta con escasa representación, de mayor a menor: Málaga, Granada, Cádiz, Córdoba, Almería y Jaén.

Modalidad o tipo. La identificación de tipos de artículos es difícil, pues hay mucha variabilidad y, en ocasiones, no está clara la frontera entre uno y otro tipo de textos. A sabiendas de que se adopta un enfoque simplificador $y$, por tanto, con riesgo de inexactitud, hemos optado por plantear tres grandes categorías: ensayos, investigaciones y experiencias.

Ensayo. Artículos cuyo propósito y contenido central es la fundamentación de unos principios teóricos; textos donde se analiza y se reflexiona sobre ciertas temáticas, llegándose a veces a realizar propuestas genéricas para su adaptación y concreción a los escenarios educativos.

Investigaciones. Artículos que presentan estudios e investigaciones desarrollados sobre una determinada temática. Incluyen información sobre el diseño y el proceso de la investigación y se plantean resultados e implicaciones. Estos estudios siguen metodologías tanto cuantitativas como cualitativas. Las primeras suelen emplear el cuestionario como técnica de recogida de datos. Entre las segundas destacan la investigación-acción y los estudios de caso.

Experiencias. Artículos que narran experiencias de distinto calado desarrolladas en las aulas; se describen y se valoran las propuestas llevadas a la práctica.

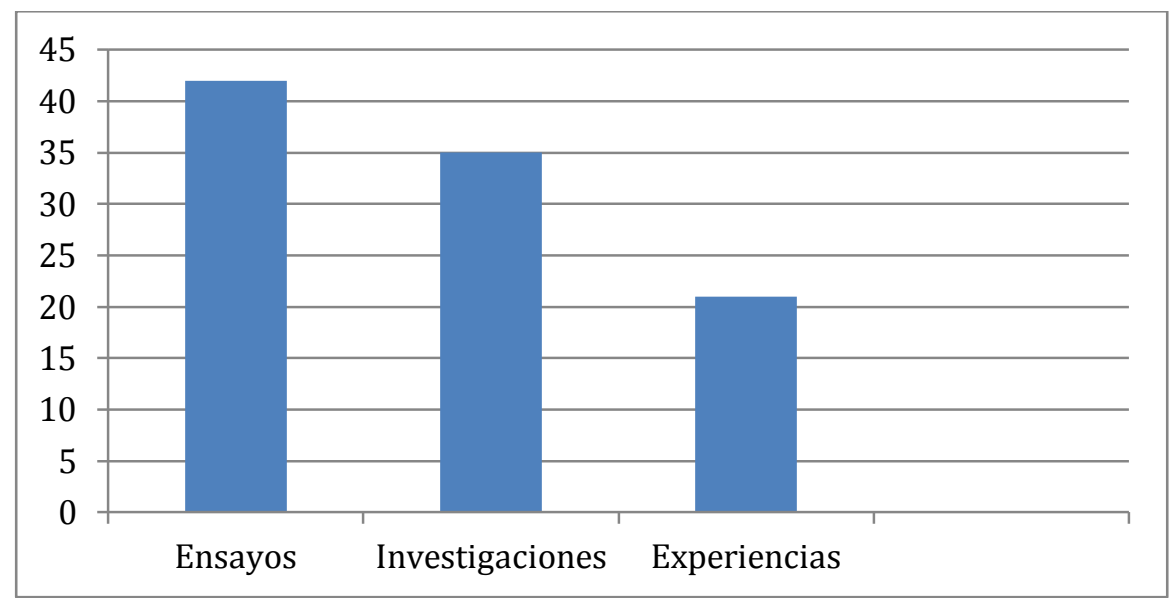

Figura 6. Distribución de artículos según tipología. Fuente: Elaboración propia.

Los datos (Figura 6) evidencian que más del 40\% de los artículos publicados en la revista son ensayos, seguidos de cerca por las investigaciones (35\%) y quedando más relegadas las experiencias (algo más del 20\% del total). 
Un análisis más detallado sobre este aspecto permite vislumbrar que la primacía de un tipo u otro de texto no es permanente a lo largo de los años. Hay períodos en los que se aprecian inversiones. Estas oscilaciones se pueden percibir con mayor nitidez en el Figura 7. Por regla general podemos afirmar que los artículos de fundamentación teórica (ensayos) dominan entre 1987 y 2005. A partir de ese momento su número disminuye ostensiblemente. Justo en esos años (2006-2015) se incrementa de forma notable el número de investigaciones. O sea, en los últimos diez años, los ensayos pierden presencia en la revista a favor de las investigaciones.

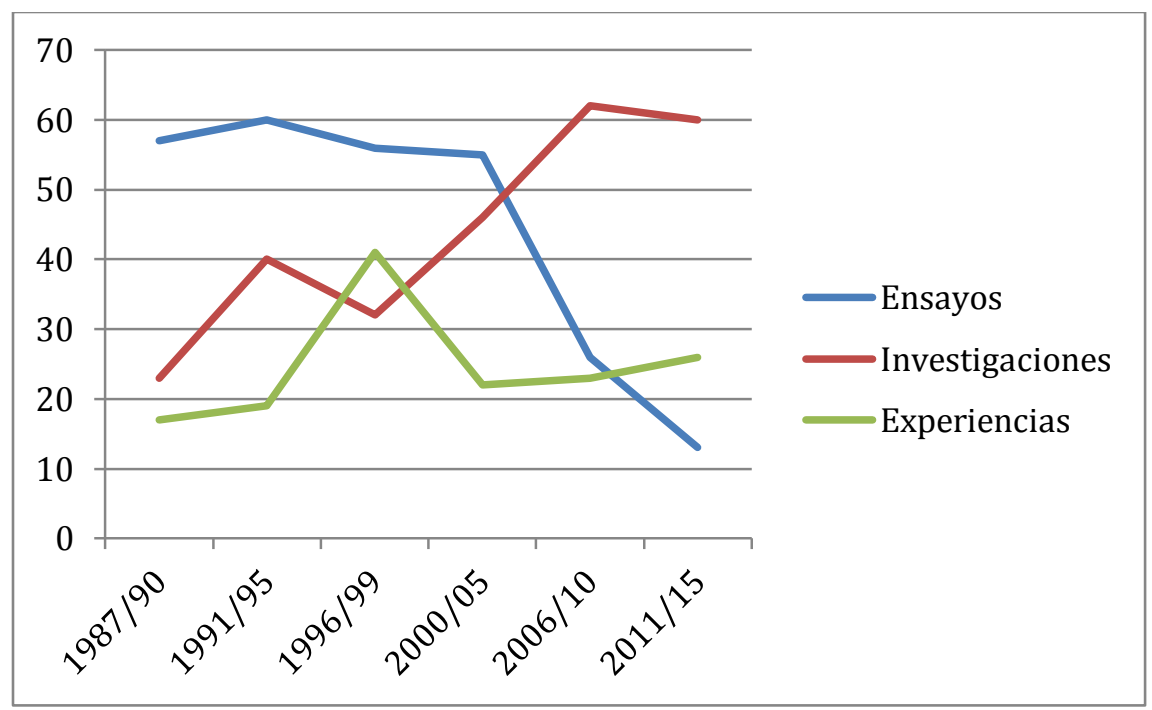

Figura 7. Distribución de tipos de artículos por años. Fuente: Elaboración propia.

En relación a las experiencias, menos numerosas, hay que destacar que la tónica desde el principio ha sido ir en aumento aunque de forma muy paulatina. Algunos números monográficos entre 1996 y 2000 sí aportan un mayor número de artículos centrados en experiencias, de ahí el pico que se observa en el gráfico 6.

A pesar del escaso número de experiencias que se publican, el Equipo de Dirección de la revista sigue empeñado en potenciar este tipo de contribuciones. En el apartado Campos de interés y secciones de la web se puede leer en la actualidad: "IE invita al profesorado innovador a exponer en esta web las experiencias de enseñanza que quiera divulgar y compartir con otros compañeros, de forma que éstos puedan adaptarlas a su aula si lo desean".

La extensión de los tres tipos de artículos es de un máximo de 40.000 caracteres; inicialmente se aludía a quince folios mecanografiados a doble espacio. De todas formas, siempre ha habido una cierta flexibilidad al respecto.

Contenido de los artículos. El análisis del contenido de los artículos es una de las tareas más complejas de cualquier análisis bibliométrico cuando se maneja una ingente cantidad de ellos. Como ya hemos anunciado, la cifra de contribuciones supera las setecientas.

Temáticas. La diversidad de temáticas abordadas en los artículos es muy amplia. Hemos de decir que algunos contenidos o temas se circunscriben casi exclusivamente a un único número monográfico, mientras otros tienen una presencia más recurrente.

En la introducción a las Actas de las V Jornadas de Estudio sobre la Investigación en la Escuela (1987), celebradas el mismo año en que nació la revista homónima, se podía leer: 
"Los procesos de investigación e innovación didáctica han puesto de manifiesto que uno de los puntos centrales de la renovación curricular es el de los contenidos. Esbozada una metodología de enseñanza más acorde con las principales teorías del aprendizaje, diseñado un "hábitat" escolar y unos recursos más ricos, concebida la escuela como un espacio social caracterizado por la libertad y la cooperación de sus miembros, en el marco de un nuevo modelo didáctico basado en la investigación, todo ello puede verse abocado al fracaso de no resolverse el tema del qué es preciso, conveniente o útil de enseñar y aprender en los centros escolares" (p. 1).

Estas líneas muestran que uno de los principales intereses de los responsables de esta publicación ha sido el tema de los contenidos escolares en un amplio sentido. Contenidos vinculados con el conocimiento científico, contenidos que precisan del establecimiento de unas "hipótesis de progresión" del conocimiento, contenidos que han de ser válidos para promover procesos de construcción de conocimientos, contenidos sobre los que el alumnado tiene ideas previas. Es decir, un enfoque de los contenidos escolares vinculado a la perspectiva constructivista. Esta circunstancia justifica que más del 17\% de los artículos publicados en la revista aborden esta temática. Además, es de enfatizar que el 70\% de esas contribuciones se realiza antes del año 2000.

Aparte de esa temática, revisados los artículos, podemos decir que casi una cuarta parte abordan cuestiones relacionadas con aspectos como: evaluación, organización y ambiente del aula, recursos didácticos, diseños curriculares, el papel del profesorado y la práctica docente en general. En torno al 36\% se centra en temas muy dispares y, en ocasiones, genéricos, como la epistemología, la formación inicial del profesorado, la investigación educativa, las reformas curriculares y las políticas educativas, etc. Cerca del 40\% se circunscriben a la enseñanza (y el aprendizaje) de contenidos de las distintas materias o áreas de conocimientos. En la Figura 8 se puede observar la supremacía de las Ciencias Sociales (Geografía, Historia, Economía, Patrimonio) y las Ciencias Naturales (Biología y Geología) sobre otras materias (Matemáticas, Música, Educación Física, Lengua, etc.). Ahora bien, si sumamos las Ciencias Naturales con Física y Química el volumen de artículos se aproxima a la mitad del total.

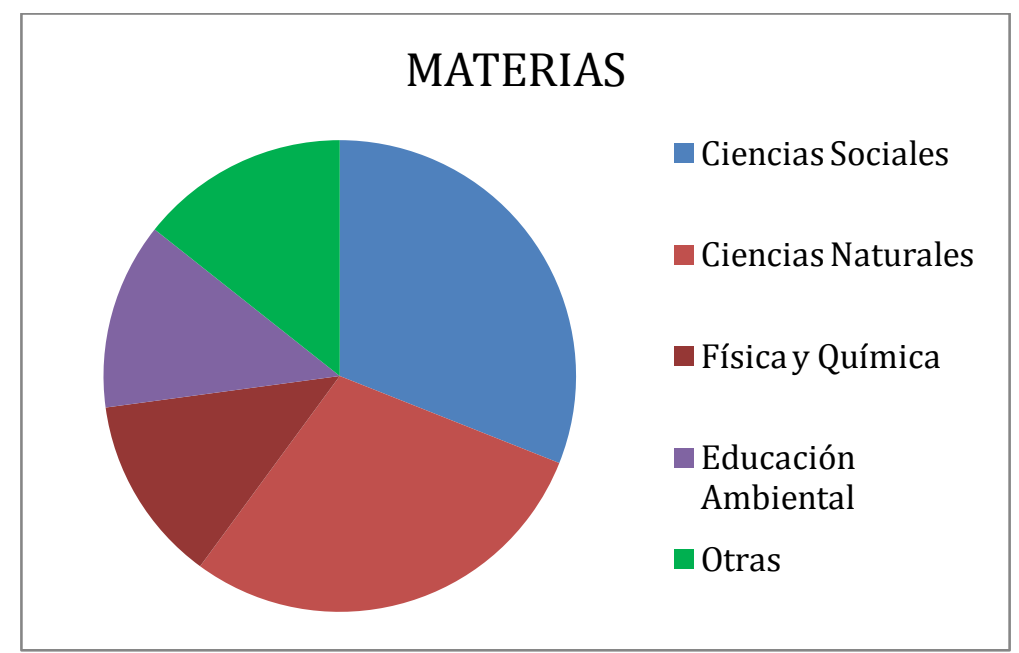

Figura 8. Materias sobre las que versa parte de los artículos. Fuente: Elaboración propia.

Etapas educativas. Uno de los aspectos del contenido de los artículos analizado ha sido la etapa educativa a la que se refería el ensayo, investigación o experiencia publicada. Es de destacar que más de la mitad de los artículos no hace alusión a ningún colectivo ni etapa concreta. La mayor parte de 
los artículos que hemos encuadrado en la categoría "ensayos" son genéricos. En esta ocasión las categorías establecidas han sido:

1. Alumnado

1.1. Alumnado de educación infantil

1.2. Alumnado de educación primaria

1.3. Alumnado de educación secundaria

1.4. Otros

2. Profesorado

2.1. Formación inicial, alumnado de universidad (Magisterio y Máster del profesorado de secundaria)

2.2. Profesorado en general

2.3. Formación permanente

3. Otros

Los datos evidencian que los protagonistas de los artículos -que sí aluden a un colectivo en particular- son en mayor medida el alumnado (64\%) (Figura 9). En particular, destaca el alumnado de educación secundaria, con un 48\% de los casos. Le sigue el alumnado de primaria, que ha sido objeto de estudio o consideración en los artículos en torno al $37 \%$ de las ocasiones. No se aprecian importantes variaciones a lo largo de los años. Por su parte, la presencia del alumnado de educación infantil es bastante menor (15\%) y más tardía; de hecho, no está presente en los primeros seis años de vida de la revista. A partir de entonces su aparición es puntual, destacando un par de números monográficos que le dieron más visibilidad (33 y 77).

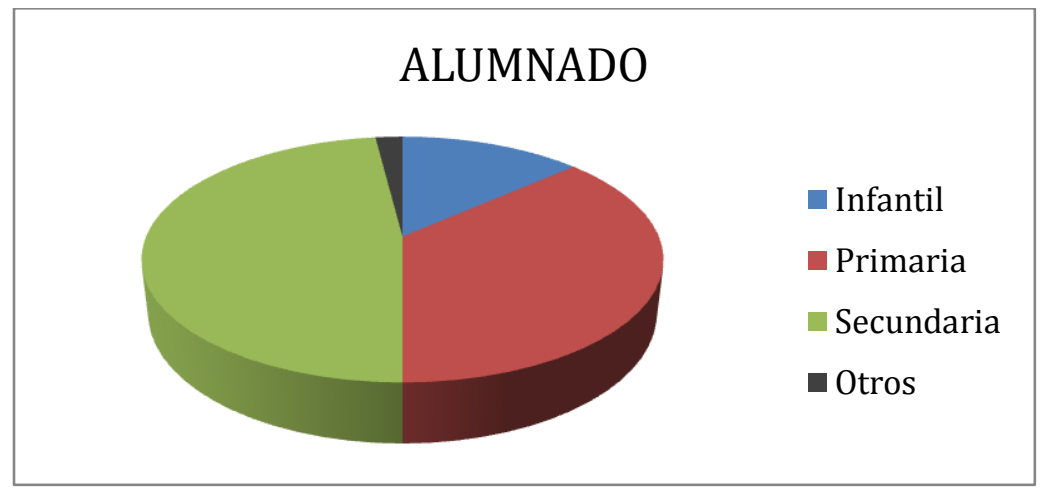

Figura 9. Etapas educativas del alumnado sobre el que se ha escrito. Fuente: Elaboración propia.

En relación al profesorado (en formación inicial y en activo), hemos de decir que son objeto del restante 36\% de los artículos. Destacan los que se centran en la formación inicial (51\%), sobre todo del profesorado de educación primaria.

Se pueden identificar dos momentos en estos casi treinta años según qué colectivo predomine más en los artículos. A partir del año 2000 aumenta el número de artículos centrados en el alumnado de educación infantil y, sobre todo, en el alumnado de Magisterio (que duplica con creces su presencia, debido en cierta medida a la aparición de ciertos monográficos). Esto es así en detrimento de otros colectivos. A partir de 2000 prácticamente no hay artículos que se ocupen del profesorado en general ni de su formación permanente. Por lo tanto, el bloque que ha ganado más peso en la revista en los últimos tres lustros ha sido el de la formación inicial del profesorado. 
Otros destinatarios presentes de forma casi testimonial en algún número de la revista son quienes se encuadran en: educación de personas adultas, educación especial o formación profesional.

\section{Para terminar...}

El análisis bibliométrico realizado y presentado en estas páginas, muestra que la revista Investigación en la Escuela, como todo proyecto vivo y dinámico, ha experimentado un interesante proceso de evolución a lo largo de tres décadas. En este periodo ha habido aciertos y fracasos, como no podría ser de otra manera. Los datos expuestos y los análisis realizados ofrecen una imagen de lo que ha sido su devenir y permiten mirar al futuro con optimismo. Eso sí, para avanzar y ser coherentes con los propósitos que animan esta publicación, conviene reflexionar sobre la información expuesta y tomar postura y trabajar en pro del tipo de revista que queremos en sintonía con la escuela que queremos.

\section{Referencias}

Alcaide Muñoz, L., Garde Sánchez, R. \& Rodríguez Bolívar, M.P. (2012). Análisis bibliométrico de una década de artículos sobre e-participación: estado actual y futuras líneas de investigación. Auditoría Pública, 56, 111-127.

Álvarez López, G. (2015). La Educación Comparada más allá de la REEC: análisis bibliométrico de la disciplina en las cinco revistas españolas afines de más impacto entre 1995 y 2014. Revista Española de Educación Comparada, 25, 19-45. DOI: 10.5944/reec.25.2015.14782.

Anta Cabreros, C. (2008). Análisis bibliométrico de la investigación educativa divulgada en publicaciones periódicas españolas entre 1990-2002. Revista Electrónica de Investigación Educativa, 10(1). Recuperado de: http://redie.uabc.mx/vol10no1/contenido-anta.html.

Ariza, T.; Granados, M.R., Ramiro, M.T. \& Gómez-García, A. (2011). Una década de la Revista Española de Orientación y Psicopedagogía: un análisis bibliométrico de su evolución. Revista Española de Orientación y Psicopedagogía, 22(1), 38-57.

Ariza, T. \& Quevedo-Blasco, R. (2013). Análisis bibliométrico de la Revista de Investigación Educativa (2000-2012). Revista de Investigación Educativa, 31(1), 31-52. DOI: 10.6018/rie.31.1.160321

Bueno Sánchez, A. \& Fernández Cano, A. (2003). Análisis cientimétrico de la productividad en la Revista de Investigación Educativa (1983-2000). Revista de Investigación Educativa, 21(2), 507532.

Cañal, P., García Díaz, J.E. \& García Pérez, F.F. (1980). El taller de Ciencias Ambientales. Cuadernos de Pedagogía, 67/68, 51-53.

Cañal, P. \& Porlán, R. (1987). Investigando la realidad próxima: un modelo didáctico alternativo. Enseñanza de las Ciencias, 5(2), 89-96.

Cañal, P. \& Porlán, R. (1988). Bases para un programa de investigación en torno a un modelo didáctico de tipo sistémico e investigativo. Enseñanza de las Ciencias, 6(1), 54-60.

De Puelles, M. (2008). Las grandes leyes educativas de los últimos doscientos años. Participación Educativa, 7, 7-15.

Fernández Cano, A. \& Bueno Sánchez, A. (1998). Síntesis de estudios bibliométricos españoles en educación. Una dimensión evaluativa. Revista Española de Documentación Científica, 21(3), 269285. 
Fuentes, J.L., Luque, D. \& López Gómez, E. (2012). Análisis bibliométrico de las revistas españolas de educación incluidas en el Journal Citation Report. Producción científica y elementos controvertidos. Teoría de la Educación. Revista Interuniversitaria, 24(1), 183-217.

García, J.-N., Sánchez, E., del Río, P. \& Arias-Gundín, O. (2002). Análisis de contenido de los 25 años de Infancia y Aprendizaje: historia de la investigación sobre desarrollo y educación. Infancia y Aprendizaje, 25(4), 403-440. DOI:10.1174/021037002762064028.

García Pérez, F.F. (2000). Un modelo didáctico alternativo para transformar la educación: el Modelo de Investigación en la Escuela. Scripta Nova. Revista Electrónica de Geografía y Ciencias Sociales, 4(64).

García Pérez, F.F. \& Porlán, R. (2000). El Proyecto IRES (Investigación y Renovación Escolar). Biblio 3W. Revista Bibliográfica de Geografía y Ciencias Sociales, 5(205).

Gómez-García, A.; Ramiro, MT.; Ariza, T. y Granados, M.R. (2012). Estudio bibliométrico de Educación XX1. Educación XX1, 15(1), 17-41

Granados, M.R.; Ariza, T. y Gómez-García, A. (2011). Estudio Bibliométrico de Aula Abierta. Aula Abierta, 39(3), 97-110.

Hernández Díaz, J.M. (2011). La renovación pedagógica en España al final de la transición. El encuentro de los movimientos de renovación pedagógica y el ministro Maravall (1983). Educació i Història: Revista d'Història de l'Educació, 18, 81-105. DOI: 10.2436/20.3009.01.86

Jiménez-Contreras, E. (2000). Los métodos bibliométricos: aplicaciones y estado de la cuestión. Actas I Congreso Universitario de Ciencias de la Documentación. Teoría, Historia y Metodología de la Documentación en España (1975-2000), pp. 757-771. Madrid.

López Calafí, J., Salvador Carreño, A. \& De la Guardia Cirugeda, M. (1998). Estudio bibliométrico de la evolución de la revista Enseñanza de las Ciencias a partir de sus fuentes de información. Enseñanza de las Ciencias, 16(3), 485-498.

López Meneses, E., Vázquez Cano, E. \& Sarasola Sánchez-Serrano, J.L. (2015). Estudio bibliométrico de Píxel-Bit, Revista de Medios y Educación (2000-2013). Pixel-Bit. Revista de Medios y Educación, 46. DOI: 10.12795/pixelbit.2015.i46.05.

MEC (1987). Proyecto para la Reforma de la Enseñanza. Madrid: MEC.

Pérez Gómez, A. \& Gimeno Sacristán, J. (1994). Evaluación de un proceso de innovación educativa. Sevilla: Junta de Andalucía.

Porlán, R. \& Cañal, P. (1986a). Una escuela para la investigación. Cuadernos de Pedagogía, 134, 45-47.

Porlán, R. \& Cañal, P. (1986b). Más allá de la investigación del medio. Cuadernos de Pedagogía, 142, 812.

Ruiz-Corbella, M., Galán, A. \& Diestro, A. (2014). Las revistas científicas de Educación en España: evolución y perspectivas de futuro. RELIEVE, 20(2). DOI: 10.7203/relieve.20.2.4361.

Ruiz-Pérez, R., Delgado López-Cózar, E. \& Jiménez-Contreras, E. (2010). Principios y criterios utilizados en España por la Comisión Nacional Evaluadora de la Actividad Investigadora (CNEAI) para la valoración de las publicaciones científicas: 1989-2009. Psicothema, 22(4), 898-908.

Sala Such, E. \& Calatayud Soler, R. (1984). Evolución y desarrollo de los contenidos pedagógicos en la Revista Bordón. Bordón, 252, 297-320.

Sancho R. (1990). Indicadores bibliométricos utilizados en la evaluación de la Ciencia y la Tecnología. Revisión bibliográfica. Revista Española de Documentación Cientifica, 13, 842-865.

Zufiaurre, B. (1994). Proceso y contradicciones de la Reforma Educativa. 1982-1994. Barcelona: Icaria. Zych, I. (2011). Análisis bibliométrico de la revista ‘Bordón’. Bordón, 63(2), 141-152. 


\title{
Sobre la Autora
}

Nombre: Soledad García Gómez

Institución: Universidad de Sevilla

Información biográfica: Profesora Titular de la Universidad de Sevilla en el Departamento de Didáctica y Organización educativa. Investigadora principal del grupo de investigación Formación y Proyecto Profesional y Vital (HUM959) del Plan Andaluz de Investigación. Principales líneas de investigación y actuación: a) Enseñanza y Aprendizaje en Formación Profesional en el Marco del Sistema Educativo; b) El Alumnado de los Ciclos Formativos. Percepciones y Expectativas de las Familias de Este Alumando; c) Formación Inicial y Permanente del Profesorado de Formación Profesional.

E-Mail: solgar@us.es

ORCID: $\underline{0000-0002-1563-8678}$

\section{Investigación en la Escuela}

Revista académica evaluada por pares y de acceso abierto

Número $88 \quad 1$ de octubre de 2016

ISSN 2443-9991

\begin{abstract}
(c)
SOMERIIGHISRESERVED Los/as lectores/as pueden copiar, mostrar, y distribuir este artículo, siempre y cuando se de crédito y atribución al autor/es y a Investigación en la Escuela, se distribuya con propósitos no-comerciales, no se altere o transforme el trabajo original. Más detalles de la licencia de Creative Commons se encuentran en http://creativecommons.org/licenses/by-nc-sa/3.0 Cualquier otro uso debe ser aprobado en conjunto por el autor/es, o Investigación en la Escuela.
\end{abstract}

Contribuya con comentarios y sugerencias en la web de la revista. Por errores y sugerencias contacte a investigacionescuela@,ddcc.uhu.es 


\title{
Investigación en la escuela
}

Consejo de dirección: Ana Rivero García (Universidad de Sevilla), Nicolás de Alba Fernández (Universidad de Sevilla), Pedro Cañal de León (Universidad de Sevilla), Francisco F. García Pérez (Universidad de Sevilla), Gabriel Travé González, (Universidad de Huelva), Francisco F. Pozuelos Estrada (Universidad de Huelva)

\author{
Dirección: Ana Rivero García y Nicolás de Alba Fernández \\ Técnico de edición: Francisco Javier López Sánchez
}

\section{Consejo editorial}

José Félix Angulo Rasco. Universidad de Cádiz Rosa Mávila Ruiz. Universidad de Sevilla Pilar Azcárate Goded. Universidad de Cádiz Juan Bautista Martínez Rodríguez. Universidad de Granada

Nieves Blanco García. Universidad de Málaga Fernando Barragán Medero. Universidad de La Laguna José Carrillo Yáñez. Universidad de Huelva José Contreras Domingo. Universidad de Barcelona. Luis C. Contreras González. Universidad de Huelva Ana $\mathbf{M}^{\mathbf{a}}$ Criado García-Legaz. Universidad de Sevilla Rosario Cubero Pérez. Universidad de Sevilla José $\mathbf{M}^{\mathbf{a}}$ Cuenca López. Universidad de Huelva Jesús Estepa Giménez. Universidad de Huelva Rafael Feito Alonso. Universidad Complutense (Madrid)

Francisco José García Gallardo. Universidad de Huelva

Soledad García Gómez. Universidad de Sevilla J. Eduardo García Díaz. Universidad de Sevilla
Fernando Hernández Hernández. Universidad de Barcelona

Salvador Llinares Ciscar. Universidad de Alicante Alfonso Luque Lozano. Universidad de Sevilla Rosa Martín del Pozo. Universidad Complutense (Madrid)

José Martín Toscano. IES Fernando Herrera (Sevilla) Jaume Martínez Bonafé. Universidad de Valencia F. Javier Merchán Iglesias. Universidad de Sevilla Emilia Moreno Sánchez. Universidad de Huelva. Rosario Ortega Ruiz. Universidad de Córdoba Antonio de Pro Bueno. Universidad de Murcia Fco. de Paula Rodríguez Miranda. Universidad de Huelva

Pedro Sáenz-López Buñuel. Universidad de Huelva Antoni Santisteban Fernández. Universidad Autónoma (Barcelona)

Emilio Solís Ramírez. Catedrático de IES.

$\mathbf{M}^{\mathbf{a}}$ Victoria Sánchez García. Universidad de Sevilla. Magdalena Suárez Ortega. Universidad de Sevilla

\section{Consejo asesor}

Manuel Area Moreira. Universidad de La Laguna

Jaume Carbonell. Director Cuadernos de Pedagogía. Barcelona

César Coll. Universidad de Barcelona

Christopher Day. Universidad de Nothingham. U.K.

Juan Delval. Universidad Nacional de Educación a Distancia

John Elliott. Universidad de East Anglia. Norwich. U.K.

José Gimeno Sacritán. Universidad de Valencia

André Giordan. Universidad de Paris VII y Ginebra

Francisco Imbernón. Universidad de Barcelona

Ángel Pérez Gómez. Universidad de Málaga

Rafael Porlán Ariza. Universidad de Sevilla

Francesco Tonucci. Instituto de Pedagogía del C.N.R. Roma

Jurjo Torres Santomé. Universidad de A Coruña 